\title{
Describing the not criminally responsible population in Alberta's history: Sociodemographic, mental health, and criminological profiles
}

\author{
Andrew M. Haag, ${ }^{\star \dagger}$ Jeremy Cheng, ${ }^{\ddagger}$ Robi Wirove
}

\begin{abstract}
This is the first paper to look at the entire population of those found Not Criminally Responsible on Account of Mental Disorder (NCR) in Alberta, Canada. The Alberta NCR Project examined longitudinal data from the NCR population to describe sociodemographic, mental health, and criminological profiles. Data were collected for the period of 1941 (i.e., the first known case in Alberta) to October 15, 2015, using archived patient chart information. The majority of Alberta NCRs have not completed high school, are diagnosed with some form of psychosis, and were found by the court to be NCR due to a violent crime. The Alberta NCR population has grown by an average of seven NCR accused per year and, of those who have reached absolute discharge, each person spent an average of 5.7 years under the Alberta Review Board (the provincial body that oversees those found NCR). Those who committed a homicide had significantly longer hospitalizations than those under every other crime category, except attempted homicide.
\end{abstract}

Key Words Not criminally responsible; the Alberta NCR project; demographics; forensic mental health; violence; mental disorder

Journal of CSWB. 2016 Nov; 1(3):68-74

www.journalcswb.ca

\section{INTRODUCTION}

In Canada, forensic psychiatric hospitals detain individuals deemed unfit to stand trial (unable to participate in criminal proceedings due to a mental disorder or mental disability) and those given a verdict of Not Criminally Responsible on Account of Mental Disorder (NCR; Latimer \& Lawrence, 2006). According to Statistics Canada (Miladinovic \& Lukassen, 2014), adult NCR cases in Canada accounted for less than one percent of the total number of adult criminal court cases processed per year. Despite the small group size, there is a lack of population level data evident in studies examining Canadian NCR people (Crocker et al., 2015; Nicholls et al., 2015). Moreover, several Canadian jurisdictions have been left largely unexamined in these studies, including Alberta. The inclusion of data from the province of Alberta would help advance an understanding of the Canadian NCR population occupying forensic psychiatric services.

Part of a Continuing Series: Proceedings of the $16^{\text {th }}$ Biennial Violence and Aggression Symposium, University of Saskatchewan, June 2016.
Familiarity with the relevant criminal responsibility legislation is key to appreciating the purview of this project. For an act to be a criminal offence, it must be a prohibited act (actus reus) that was done with the intention or knowledge that it was wrong (mens rea) (Ferguson \& Ogloff, 2011). Section 16 of the Criminal Code of Canada outlines the defence for someone whose behaviour was impacted by a mental disorder at the time of a criminal offence. Section 16 (Criminal Code, 1985) states:

(1) No person is criminally responsible for an act committed or an omission made while suffering from a mental disorder that rendered the person incapable of appreciating the nature and quality of the act or omission or of knowing that it was wrong.

Under Canadian Law, one must be mentally ill and meet one criterion of the aforementioned legal test to be found NCR. Both historically and within other jurisdictions the NCR option has been, and currently may be, referred to as the insanity defence (Simon \& Ahn-Redding, 2008). Nevertheless, these individuals will be considered NCR within the bounds of this paper. 
Section 672.54 (b) of the Criminal Code provides the provincial or territorial review board and the court with the authority to independently enact legal conditions for those found NCR. Following an NCR finding, the court may either issue a disposition immediately or to refer the case and responsibility to a review board. In the case of Alberta, Canada, the legal authority typically overseeing those who have been found NCR is the Alberta Review Board (ARB). It is believed that the overwhelming majority of NCR accused in Alberta have fallen under the authority of the ARB, but not all (Latimer \& Lawrence, 2006).

Under section 672.54 of the Criminal Code, there are three dispositions available to a court or Review Board: (1) an absolute discharge, (2) a conditional discharge, or (3) detention in custody in a hospital. In the event of an absolute discharge, the NCR person would no longer be under the jurisdiction of a review board and would return to the community free of legal conditions. With a conditional discharge, the person found NCR would be supervised in the community with restrictions imposed on their liberty by a review board. Finally, a disposition of detention in custody (sometimes referred to as a full warrant) in a hospital refers to a NCR person being held within a secure forensic psychiatric facility.

Throughout much of Canadian history, the Section 16 standard has remained largely unchanged until 1992, when the passing of Bill C-30 and other landmark court cases (R. v. Swain, 1991; Winko v. British Columbia, 1999) altered the assessment and processing of NCR accused. Penney, Morgan, and Simpson (2013) identified that the number of people being declared NCR has increased since the Supreme Court mandated legislative reforms in 1992. Moreover, a greater heterogeneity in the offending and psychiatric profiles was found for NCR people. This was not a phenomenon exclusive to Canada, as the United States and 15 European Union member countries also witnessed a rise in the heterogeneity of NCR profiles. With these legislative changes, Penney et al. (2013) suggested that further research was required on the sociodemographic characteristics of individuals found NCR.

\section{SOCIODEMOGRAPHIC, MENTAL HEALTH, AND CRIMINOLOGICAL DATA IN THE LITERATURE}

The literature offers some descriptive data on individuals found NCR in Canada, but is lacking in-depth research on several jurisdictions. This is thought to be problematic because NCR accused are a unique population that face complex legal and mental health challenges requiring high-cost care and services. The issue is further compounded by the growth of this population (Penney et al., 2013) and its resulting strain on the forensic mental health system (Crocker, Braithwaite, Côté, Nicholls, \& Seto, 2011). A deeper study of this population can help institutions identify, plan, and deliver effective services for the specific needs of each jurisdiction.

The Department of Justice (Latimer \& Lawrence, 2006) examined a sample of Canadian NCR accused who passed under the review boards between 1992 and 2004. There was a total of 6,802 NCR cases in the seven participating jurisdictions. There was an increase of 2,500 NCR review board cases (an approximately 50\% increase), indicating substantial growth in this population. There were a greater number of males $(84 \%)$ than females $(16 \%)$, with a large group $(46.4 \%)$ belonging to the 26- to 40 -age range. Of the Aboriginal NCR accused $(4.2 \%)$, the median ages of males (29 years) and females (32 years) were younger than non-Aboriginal males (35 years) and females (38 years). Over three-quarters of the most serious crimes were violent crimes, the most common of which were assault $(42.4 \%)$, threats $(10.6 \%)$, homicide $(7.2 \%)$, and attempted homicide (6.5\%). Sexual crimes accounted for $4.3 \%$ of total offences, of which youth $(30.1 \%)$ held a higher proportion of these charges than adults (4.8\%). Males had more sexual offences than females, with Aboriginals (11.3\%) committing more than non-Aboriginals (5.4\%). Over one-third of NCR accused remained under a review board for more than ten years, with $24.9 \%$ staying five to ten years, and $30.9 \%$ staying one to five years. Aboriginal NCR accused had considerably longer stays under a review board than non-Aboriginals. NCR accused charged with sexual offences were more likely to stay longer than those charged with violent or nonviolent offences. Over half of NCR accused were diagnosed with schizophrenia. The next most common diagnoses included substance abuse disorders (31.4\%), affective disorders (28.1\%), and personality disorders (19.2\%).

Statistics Canada (Miladinovic \& Lukassen, 2014) reported on the NCR and adult criminal data representing 10 provinces and territories in Canada between 2005 and 2012. From available data, there were a total of 1,908 recorded adult NCR cases with an average of 252 to 292 cases completed per year. Overall, NCR adult cases in Canada were stable with variations of approximately 7.5 to 9.1 cases per 10,000 adult criminal court cases. In approximately two-thirds of all NCR adult cases, the most serious offences involved crimes against persons. Adult NCR accused appear to be slightly older than non-NCR criminal cases, with the median age at the time of offence being 34 years. The most common age group for NCR cases ranged from 25-34 years and involved more male accused $(87 \%)$ than female accused $(13 \%)$. The median duration of time from the initial court appearance to case completion in adult criminal court cases was longer for NCR verdicts (132 days) than non-NCR verdicts (113 days). Adult NCR cases were typically completed within 121-240 days, with a minority of cases taking more than 240 days, and the remainder concluding within 30 days.

The National Trajectory Project (NTP) (Crocker et al., 2015; Nicholls et al., 2015) examined NCR accused in Canada across Quebec, Ontario, and British Columbia. There was a greater proportion of male $(84.4 \%)$ to female (15.6\%) NCR accused. This finding converges with several other studies (Livingston, Wilson, Tien, \& Bond, 2003; Latimer \& Lawrence, 2006; Miladinovic \& Lukassen, 2014). The average age reported was 36.56 years, with the age of women (40.6) being older at the time of index offence than men (35.8). Approximately one-half graduated from high school overall; more women $(60.1 \%)$ graduated than men $(47.3 \%)$. The data indicated that most persons found NCR were single $(83.6 \%)$, with the remainder being in a relationship $(16.4 \%)$. The primary diagnosis at the time of NCR finding included psychotic spectrum disorder $(70.9 \%)$, mood spectrum disorder $(23.2 \%)$, substance abuse disorder $(30.8 \%)$, personality disorder $(10.6 \%)$, and combinations of the previous. Index offences at NCR finding involved a greater number of crimes against persons $(64.9 \%)$ 
than property offences $(16.9 \%)$ and other criminal code violations (18.2\%). Supporting other studies, assault accounted for one-quarter to one-third of all index offences across the three provinces (Livingstone et al., 2003; Crocker et al., 2011).

\section{CONTEXT OF THE CURRENT PROJECT}

Current literature describing the Canadian NCR population is missing a detailed examination of Alberta. The goal of this publication was to help fill this gap by describing the sociodemographic, mental health, and criminological profiles of the entire Alberta NCR population. Data collection followed archival means when extracting NCR patient information. Collaborators reviewing patient charts coded data onto a password-protected and encrypted database. The data were then checked, analyzed, and reported. To the authors' knowledge, The Alberta NCR Project is the first research of its kind to examine an entire forensic population.

\section{METHODS}

\section{Design}

The Alberta NCR Project collected longitudinal data on persons found NCR or Insane who have passed under the authority of the ARB. The principal author made numerous attempts to ensure that the information acquired for this study was complete. Throughout Alberta's history, the primary location where NCR inpatients have been housed has been at Alberta Hospital Edmonton (AHE). This is a provincially operated psychiatric hospital under Alberta Health Services, providing inpatient and community mental health services. AHE functions as an assessment and treatment facility for voluntary, formal, or criminal code referrals. The primary site for outpatient or community supervision of NCRs has been at Forensic Assessment and Community Services (FACS) in Edmonton, Alberta. Given this arrangement, both the Provincial Director (who oversees review board cases for the entire province) and the Clinical Director (who oversees review board cases at either AHE or FACS) store their files at AHE. Within these files, copies of all reports submitted to the ARB are also archived therein. Moreover, AHE maintains copies of all active dispositions in Alberta for front-line emergency personnel. Given the above, the principal author has overseen a review of all known paper and electronic files at AHE, FACS, and the ARB.

\section{Procedure}

For each case, trained collaborators coded patient chart data onto a shared encrypted database. To ensure consistency and quality, collaborators were instructed to code from primary legal documentation and formal psychiatric reports when possible. Collaborators were comprised of senior undergraduate students, graduate students, doctoral residents, and medical residents. Data checks were performed regularly to ensure consistency of approach and to resolve challenging or atypical cases. Notable strategies for this include a minimum of two reviews for each patient chart, accessing the same patient data from different institutional sources, and frequent team discussion at AHE. The data for this project were compiled, processed, and reported using the Statistical Package for the Social Sciences (IBM Corp, 2010).

\section{Sources of Data}

Sources of data for this paper came directly from reviewing the following information: (1) patient charts of every ARB disposition pertaining to those found NCR or Insane, (2) AHE and FACS patient charts that include psychological and psychiatric reports on Alberta's NCRs, and (3) AHE's internal database of demographic information on AHE patients. All of these sources combined are thought to contain information on all of the NCRs in Alberta throughout history, regardless of the provincial hospital sites at which any one NCR may have been housed. Three primary categories of data were coded: sociodemographic information (age, birth date, sex, race, education, marital status), clinical information (psychiatric diagnosis), and criminal offence information (date of NCR verdict, location(s) of offence, index offence(s), date of index offence, and yearly warrant status).

\section{Psychopathology}

Diagnoses were coded using court-ordered psychiatric assessments for the index offence (i.e., the offence(s) for which one was found to be NCR) and/or annual follow-up reports submitted to the ARB. Given the abundance of diagnoses throughout the span of patient hospitalization, only the most recent diagnoses were coded. At times, non-standard symptomatology and patient descriptors informed coding in the absence of formal diagnosis in psychiatric reports. When there were nonstandard symptom descriptions in the documents, ultimately the lead investigator, a registered psychologist, was involved in coding the diagnostic symptoms to ensure consistency. Given that the data collected spans from 1941 (i.e., the first known NCR case) to 2015, multiple diagnostic systems were employed by various mental health professionals. Diagnoses were coded individually and ultimately aggregated into broader diagnostic categories for analysis. The broader diagnostic categories included: psychosis, mood, organic, intellectual impairment, substance use, and other (i.e., developmental disorders, dementia, post-traumatic stress disorder). Unless a diagnosis accounted for greater than 5\% of the population, it was listed under "other." Cumulative percentages exceed $100 \%$ because multiple diagnoses were coded for some cases.

\section{Criminal Information}

Index offence. Index offences were coded using legal dispositions issued from the court. When coding the types of crimes that NCR accused were implicated in, every offence type was counted for with every NCR patient. As a result, cumulative percentages exceeded $100 \%$ because of multiple index offences. If an NCR patient had more than one charge for the same index offence, the offence was only counted once. For instance, if a person was convicted of two assaults and one weapons offence, then this would be coded as the patient being found NCR for the violent and weapons offence types. Sexual offences included the following categories: attempted sexual assault, sexual assault, indecent act, and sexual touching. Direct violent offences included the following categories: assault, assault with a weapon, attempting to choke, unlawful wounding, direct threats to another person, hostage taking, kidnapping, and unlawful confinement. The category of weapons offences included possession offences 
or careless use of a firearm. Offences directly related to intoxicants included: impaired driving, failure to provide a breath sample, and public intoxication. The category of other offences included break and enter, property crime, extortion, mischief, driving offences, administrative justice offences, resist arrest, negligence offences, and fraud. Table I illustrates the distribution of index offences.

Geographic location of index offence. The geographic location of the index offence was coded using court issued dispositions. Location of index offence was ultimately truncated down into three categories: Red Deer or south, north of Red Deer, and out of province. The location of Red Deer, Alberta was chosen because it is a common dividing location between Alberta's two major metropolitan centres (i.e., Edmonton and Calgary).

Length of time to NCR verdict. The authors tracked the length of time it took for someone to become NCR from the date of the earliest index offence. Collaborators coded the date of the earliest index offence and the date of the NCR verdict from court-issued dispositions. The length of time was derived from the difference between these two dates.

Severity of offence. The authors considered the time to NCR verdict and absolute discharge by index offence using the following order of seriousness: (1) homicide, (2) attempted homicide, (3) sexual violence, (4) direct violence, and (5) all other crimes. Individual offences were coded and ultimately aggregated into the broader categories.

Length of time to absolute discharge. The length of time from NCR verdict to absolute discharge was tracked by coding yearly changes to warrant statuses for each case. Collaborators used court- or ARB-issued dispositions for consistency in coding. Categories of coding included: absolute discharge, conditional discharge, full warrant, NCR overturned, transferred out of province, AWOL, and died while under warrant. There was attrition in the database: 40 persons died while under the jurisdiction of the ARB, 9 persons successfully overturned their NCR finding, 21 persons transferred out of Alberta, 4 persons went on Absence Without Leave, and 5 were unknown due to missing information.

\section{Analytic Strategy}

Descriptive information was analyzed by calculating frequencies statistics. Between group differences were calculated using ANOVA and subsequent Tukey analysis.

\section{Ethics}

Ethics approval for this research was acquired from both Alberta Health Services and the Research Ethics Office of the University of Alberta.

\section{RESULTS}

\section{Sociodemographic Characteristics}

The total number of NCR persons who passed under the authority of the ARB up until October 15, 2015 was 546. The ARB processed their first NCR case in 1941. As of October 15, 2015, the ARB had 191 active NCR cases under their authority.
TABLE I Distribution of index offences pertaining to Alberta NCRs

\begin{tabular}{lc}
\hline \multicolumn{1}{c}{ Type of offence } & $\mathbf{n}(\%)$ \\
\hline $\begin{array}{l}\text { Direct violence (excluding sexual offences, } \\
\text { homicide, and attempted homicide) }\end{array}$ & $256(46.9)$ \\
Homicide & $101(18.5)$ \\
Weapons & $91(16.6)$ \\
Attempted homicide & $58(10.6)$ \\
Arson & $36(6.6)$ \\
Sexual offences & $34(6.2)$ \\
Robbery & $32(5.9)$ \\
Criminal harassment & $17(3.1)$ \\
Offences directly related to intoxicants & $4(.7)$ \\
Drug possession/trafficking & $2(.4)$ \\
Counsel to commit murder & $1(.2)$ \\
Conspiracy to commit murder & $1(.2)$ \\
All other offences & $179(32.7)$ \\
\hline
\end{tabular}

The authors examined the growth of the NCR population by taking the difference between the number of new NCR findings (entering) and the number of absolute discharges (exiting) in any one calendar year. It was found that from 2000 until 2014, there was a net increase in the NCR population in Alberta by 101 persons (i.e., a net increase of 7.2 cases per year, on average).

There were $459(84 \%)$ males and $87(16 \%)$ females in the population. The mean age of Alberta NCRs at the time of their NCR verdict was 35.3 years, with males (34.8 years) being slightly younger than females (37.8 years). Median ages were 33 and 38 for males and females, respectively. Mean age at the time of the NCR verdict was not statistically different by sex in the population $[\mathrm{F}(1,545)=3.817, p=.051]$. Of the 546 cases, $13(2.38 \%)$ were below the age of 17.9 years at the time of the NCR verdict.

Regarding educational level, 367 (67\%) individuals did not complete high school. For the remainder, 164 (30\%) either completed high school or went beyond a high school level. Data on education level were missing for 15 cases. For those who did not complete high school, there were more males $(71 \%)$ than females (58\%). For those who achieved high school or beyond, there were more females (42\%) than males (29\%). The Alberta NCR population has had the following racial composition: Caucasian (72.9\%), African-Canadian (4.4\%), Hispanic (2.4\%), Asian (4.8\%), Aboriginal (8.6\%), Middle Eastern (1.5\%), East Indian (3.8\%), Caribbean (0.4\%), and unknown (0.3\%). Regarding marital status, $16.7 \%$ have been married or common-law, $83.2 \%$ single, and for $0.2 \%$ their marital status was unknown.

\section{Mental Health Characteristics}

Psychiatric diagnoses were acquired for all but one missing case in the population. Approximately three-quarters of the NCR population in Alberta were diagnosed with a psychotic disorder. Table II illustrates the distribution of diagnoses by sex for the Alberta NCR population. For those who received an absolute discharge, Table III shows the time to discharge by mental disorder. It should be noted that the 
mental disorder category was not mutually exclusive, and that any one patient may have been diagnosed under multiple diagnostic categories.

\section{Criminological Characteristics}

Index offence at the time of NCR verdict was found for all but two cases. Table I illustrates the percentage of NCR accused by type of offence. Table IV shows the time to NCR verdict from the date earliest index offence.

Regarding geographic area of index offences, NCRs in Alberta were noted to have committed their index offences in the following locations: (1) Red Deer and south $(n=227$, $42 \%)$, (2) north of Red Deer (excluding Red Deer) ( $\mathrm{n}=288$, $53 \%)$, and (3) out of province $(n=31,6 \%)$.

The length of time that elapsed from NCR verdict until the date of absolute discharge was analyzed. As of October 15, 2015, there had been 277 known absolute discharges in Alberta. Of those cases, only one was known to have been given an absolute discharge at the time of the NCR verdict from the court. For NCR patients who obtained an absolute

TABLE II Diagnoses observed in the Alberta NCR population by sex

\begin{tabular}{lccc}
\hline \multicolumn{1}{c}{ Mental disorder } & $\begin{array}{c}\text { Total } \\
\text { population } \\
\text { (\%) }\end{array}$ & $\begin{array}{c}\text { Male } \\
\text { (\%) }\end{array}$ & $\begin{array}{c}\text { Female } \\
\text { (\%) }\end{array}$ \\
\hline Psychotic disorder & 75.6 & 75.2 & 78.2 \\
Mood disorder & 29.1 & 26.6 & 42.5 \\
Substance use disorder & 39.2 & 40.7 & 31.0 \\
Antisocial personality disorder & 15.1 & 16.5 & 6.9 \\
Intellectual impairment & 5.1 & 5.5 & 3.4 \\
Other & 26.7 & 26.4 & 28.7 \\
\hline
\end{tabular}

discharge, the mean length of time in months to absolute discharge was 68.8 months $(S D=69.9)$ or 5.7 years. For those currently under the ARB who had not reached an absolute discharge, the average time under the ARB was 8.6 years as of October 15, 2015. Table V is a summary of the time to absolute discharge by severity of index offence. There was a significant difference in the length of time spent under the ARB by severity of offence $[\mathrm{F}(4,272)=14.879, p=.000]$. Those found NCR for homicide have spent more time under the ARB than those found NCR for sexual offences, violent offences, and the 'all others' category. Additionally, those who were found NCR for attempted homicide spent more time under the ARB than those in the "all others" category.

When analyzing the impact of mental disorder on the offending profile, there was no difference in crimes committed across all disorders. Crimes held the general trend of being mostly homicide and direct violence, with a minority of cases evenly divided into attempted homicide, sexual violence, and all other crimes.

\section{DISCUSSION}

The aim of this paper was to describe the Alberta NCR population concerning its sociodemographic, mental health, and criminological profiles. Relative to other researched Canadian jurisdictions, Alberta's NCR population compares closely in terms of age, sex, marital status, and mental health profiles, but not educational levels and Aboriginal composition (Latimer \& Lawrence, 2006; Miladinovic \& Lukassen, 2014; Crocker et al., 2015). Only one-third attained a high school diploma compared to over one-half as reported in Ontario, Quebec, and British Columbia (Crocker et al., 2015). Moreover, Alberta has a higher proportion of Aboriginal NCRs $(8.6 \%)$ when compared to other provinces, a trend

TABLE III Time to absolute discharge in months by mental disorder

\begin{tabular}{lcccccccc}
\hline & $\boldsymbol{n}$ & Mean & SD & Min & Max & $\mathbf{Q}_{\mathbf{1}}$ & $\mathbf{Q}_{\mathbf{2}}$ & $\mathbf{Q}_{\mathbf{3}}$ \\
\hline Psychotic disorder & 194 & 80.9 & 72.6 & 0 & 372 & 28.8 & 63 & 108.8 \\
Mood disorder & 83 & 60.6 & 73.1 & 0 & 372 & 16 & 42 & 74 \\
Substance use disorder & 78 & 64.5 & 67.4 & 0 & 372 & 17 & 52 & 78.3 \\
Intellectual impairment & 7 & 19.1 & 39 & 0 & 105 & 0 & 1 \\
ASPD & 24 & 60.2 & 61.1 & 0 & 264 & 12.5 & 52 & 77.8 \\
Other & 63 & 39.7 & 43.8 & 0 & 245 & 6 & 29 & 59 \\
\hline
\end{tabular}

Table IV Time from earliest index offence to NCR finding, in months

\begin{tabular}{lccccccccc}
\hline & Mean & $\begin{array}{c}\text { Male/ } \\
\text { female }\end{array}$ & SD & Min & Max & $\mathbf{Q}_{\mathbf{1}}$ & $\mathbf{Q}_{\mathbf{2}}$ & $\mathbf{Q}_{\mathbf{3}}$ & $\begin{array}{c}\boldsymbol{n} \\
\text { (\% of pop) }\end{array}$ \\
\hline Homicide & $14.1^{\mathrm{a}}$ & $83 / 18$ & 13.2 & 1 & 88 & 6 & 10 & 18 & $100(18.3)$ \\
Attempted homicide & 11.9 & $49 / 9$ & 14 & $<1$ & 83 & 4.8 & 8 & 13.25 & $58(9.9)$ \\
Sexual violence & 13.3 & $34 / 0$ & 12.8 & $<1$ & 52 & 6 & 9 & 16 & $33(6)$ \\
Direct violence & $8.8^{\mathrm{ab}}$ & $215 / 41$ & 9 & $<1$ & 75 & 4 & 6 & 10.75 & $256(46.8)$ \\
All other crimes & $11.4^{\mathrm{b}}$ & $117 / 23$ & 13.4 & $<1$ & 114 & 4 & 7 & 13.25 & $178(32.6)$ \\
\hline Total population & 0.4 & $459 / 87$ & 11.5 & $<1$ & 114 & 4 & 7 & 12 & $544(99.6)$ \\
\hline
\end{tabular}

a Significant $p=.000$.

b Significant $p=.015$. 
TABLE V Time in months to absolute discharge by most serious offence

\begin{tabular}{lccc}
\hline & Mean & $\boldsymbol{n}$ & SD \\
\hline Homicide & $123.3^{a}$ & 45 & 84.4 \\
Attempted homicide & $84.9^{\mathrm{b}}$ & 24 & 71.5 \\
Sexual violence & $46.7^{\mathrm{a}}$ & 19 & 61 \\
Direct violence & $68.3^{\mathrm{ac}}$ & 130 & 65.8 \\
All other crimes & $44.5^{\mathrm{abc}}$ & 59 & 29.7 \\
\hline Total population & 68.8 & 277 & 69.9 \\
\hline
\end{tabular}

Difference between above categories $a, b, \& c$ were significant at $p=<.01$.

that follows Alberta's higher Aboriginal base rates (Statistics Canada, 2011). Despite this, the Alberta NCR Aboriginal composition is still substantially lower than what is typically found in criminal justice settings (Latimer \& Lawrence, 2006; Statistics Canada, 2006). Supporting research on NCR sex differences in mental health profiles (Nicholls et al., 2015), substance abuse disorder and antisocial personality disorder were more prevalent in males than females. Mood disorders were found to be twice as prevalent in females than males, also concurrent with research (Nicholls et al., 2015; Ferranti, McDermott, \& Scott, 2013; Friedman, Hall, \& Sorrentino, 2013). Contrary to public perception on NCR people, the type of mental disorder does not dictate the kinds of crimes that are subsequently committed. Indeed, similar offending profiles were seen across all diagnostic categories. The type of mental disorder, however, appeared to influence the length of time under the ARB. For those who received an absolute discharge, a psychotic diagnosis led to the longest average time under the ARB (80.2 months), whereas the shortest duration (19.1 months) was found for those with an intellectual impairment diagnosis. These phenomena may be due to the chronic nature of psychotic disorders, and so longer periods of stay are required for remediation.

Index offences for the Alberta NCR population were comprised mostly of crimes against persons, supporting other studies on NCR groups (Livingston et al., 2003; Crocker et al., 2011; Crocker et al., 2015; Latimer \& Lawrence, 2006; Miladinovic \& Lukassen, 2014). Differing from some of these studies, however, were the distribution of these offences. Accounting for $80 \%$ of all crimes, the Alberta NCR population held a greater number of crimes against persons than Ontario, Quebec, and British Columbia (64.9\%) (Crocker et al., 2015). Moreover, there was a higher composition of homicides and attempted homicide $(\sim 28 \%)$, and sexual offences $(\sim 6 \%)$ compared to the previous jurisdictions $(10 \%$ and $2.3 \%$, respectively). Concurrent with Statistics Canada (Miladinovic \& Lukassen, 2014), the length of time to NCR verdict for assault (most common index offence) is an average of eight months. Contrary to some media speculation and lay beliefs, the NCR defence does not allow evasion of consequence. Alberta NCR accused spend an average of almost six years under warrant across all index offences, with those not yet given a discharge spending over eight years, on average, under warrant. Converging with other research, length of hospitalization (detention) increases with severity of the offence (Livingstone et al., 2003). In this study, those who committed a homicide spend over a decade, on average, under warrant.

\section{Implications}

Among the Alberta NCR population reviewed here, over half of those found NCR had not completed high school, either by traditional school attendance and graduation or through a Graduate Equivalency Diploma examination. Decision makers would be wise to ensure that there are resources in place to assist this population with educational upgrading, as this is potentially a criminogenic need.

Further implications for resourcing involve the availability of hospital beds and gender-specific services. In line with other research (Latimer \& Lawrence, 2006), the current data support that the Alberta NCR population has been growing since the year 2000. Assuming population growth remains consistent into the future, decision makers can reasonably expect that there will be an increasing need for additional NCR beds and services. Given that this study provided geographic data of those found NCR, this study can assist decision-making regarding the location of future servicing needs. The data also displayed a need for genderspecific treatment services, as males and females had some differences in diagnostic profiles.

Much like other jurisdictions across Canada, the Alberta NCR population is heterogeneous and present concerns that lay within having a diverse group (Crocker et al., 2015). For forensic service providers, it is essential to keep an account of emergent and recurring issues on victimization, violence, and other forms of manipulation.

\section{Strength and Limitations}

This is the first study providing an in-depth examination of the NCR population in Alberta's history. One identifiable strength is the potential of its external validity. Given that this was population-level data from 1941 to October 15, 2015, there is no significant concern in generalizing any of these results within Alberta. By extension, these results are generalizable across Canada to the extent that the respective populations are similar to the Alberta population.

As a limitation, this study had no way of comprehensively acquiring data on NCR accused who were given an absolute discharge by the courts (not the review boards). This is due to such persons never having been under the attention of the ARB; hence, the authors had no way of tracking such cases. It is believed that such situations are rare, but there was no way of verifying how often such a situation occurred.

As with many archival studies, there was the limitation of having a greater likelihood of missing data than a prospective approach. For instance, older cases reflecting a period of less stringent documentation practices may provide sparse and interpretive data. Comparatively, modern-day practices using in-depth interviews and assessment protocols would yield more detailed and reliable data.

\section{Future Directions}

The Alberta NCR Project will continue to examine many research questions upon more thorough analysis and with the addition of more data. Given the evidence for a growing NCR population, one study will examine the impact of Supreme Court decisions on the length of hospitalization to discharge. Other studies will look at risk-assessment tools, specifically the qualities of its psychometric properties, how they compare with one and another, and the merits of their 
approaches. Examining recidivism rates within the Alberta NCR population will take a detailed look at offence types, victims, and opportunities when they may occur. Another project will investigate the predictors of ARB decisions when allocating privileges in liberty and disposition statuses. This project should help monitor the ARB, and track the impact of legal and mental health policy.

\section{ACKNOWLEDGMENTS}

Special acknowledgements to Chayse Haldane, Troy Rieck, Alicia MacNeil, and Arielle Boyes for their assistance. No funding was received for the completion of this project.

\section{CONFLICT OF INTEREST DISCLOSURES}

The authors declare that they have no conflicts of interest.

\section{AUTHOR AFFILIATIONS}

*Alberta Health Services and ${ }^{\dagger}$ Department of Psychiatry, University of Alberta, Edmonton, AB; ; Department of Psychology, University of Saskatchewan, Saskatoon, SK, Canada.

\section{REFERENCES}

Criminal Code. (1985). RSC., 1985, C. C-46. PART II: Offences against public order treason and other offences against the Queen's authority and person. Ottawa: Statutes and Regulations, Government of Canada.

Crocker, A. G., Braithwaite, E., Côté, G., Nicholls, T. L., \& Seto, M. C. (2011). To detain or to release? Correlates of dispositions for individuals declared not criminally responsible on account of mental disorder. Canadian Journal of Psychiatry, 56151, 293-302

Crocker, A. G., Nicholls, T. L., Seto, M. C., Charette, Y., Côté, G., \& Caulet, M. (2015). The national trajectory project of individuals found not criminally responsible on account of mental disorder in Canada. Part 2: The people behind the label. Canadian Journal of Psychiatry, 60131, 106-116.

Ferguson, M., \& Ogloff, J. R. P. (2011). Criminal responsibility evaluations: Role of psychologists in assessment. Psychiatry, Psychology and Law, 18(1), 79-94. Available from: http://doi.org/10.1080/13218719.2 010.482952
Ferranti, J., McDermott, B. E., \& Scott, C. L. (2013). Characteristics of female homicide offenders found not guilty by reason of insanity. Journal of the American Academy of Psychiatry and the Law, 41 (4), 516-522.

Friedman, S. H., Hall, R. C. W., \& Sorrentino, R. M. (2013). Commentary: Women, violence, and insanity. Journal of the American Academy of Psychiatry and the Law, 41 (4), 523-528. Retrieved from http:/ / www. scopus.com/ inward/record.url?eid=2-s2.0-84890293162\&partner ID=†ZO†×3yl

IBM Corp. (2010). IBM SPSS statistics for Windows (Version 19). Armonk, NY: IBM Corp.

Latimer, J., \& Lawrence, A. (2006). The review board systems in Canada: Overview of results from the Mentally Disordered Accused Data Collection Study. Ottawa: Department of Justice Canada.

Livingston, J. D., Wilson, D., Tien, G., \& Bond, L. (2003). A follow-up study of persons found not criminally responsible on account of mental disorder in British Columbia. Canadian Journal of Psychiatry, 48(6), 408-415.

Miladinovic, Z., \& Lukassen, J. (2014). Verdicts of not criminally responsible on account of mental disorder in adult criminal courts, 2005/20062011/2012. Ottawa: Statistics Canada. Retrieved from http://www. statcan.gc.ca/pub/85-002-x/2014001/article/14085-eng.htm

Nicholls, T. L., Crocker, A. G., Seto, M. C., Wilson, C. M., Charette, Y., \& Côté, G. (2015). The national trajectory project of individuals found not criminally responsible on account of mental disorder. Part 5: How essential are gender-specific forensic psychiatric services? Canadian Journal of Psychiatry, 60(3), 135-145.

Penney, S. R., Morgan, A., \& Simpson, A. I. F. (2013). Motivational influences in persons found not criminally responsible on account of mental disorder: A review of legislation and research. Behavioral Sciences and the Law, $31(4), 494-505$

R v Swain [1991] 1 S.C.R. 933. Ottawa: Supreme Court of Canada.

Simon, R. J., \& Ahn-Redding, H. (2008). The insanity defense, the world over. Toronto: Lexington Books.

Statistics Canada. (2006). Census 2006 long form. Ottawa: Statistics Canada. Statistics Canada. (2011). Census 2011 long form. Ottawa: Statistics Canada. Winko v British Columbia (Forensic Psychiatric Institute) [1999] 2 S.C.R. 625. Ottawa: Supreme Court of Canada. 